This item was submitted to Loughborough's Research Repository by the author.

Items in Figshare are protected by copyright, with all rights reserved, unless otherwise indicated.

\title{
Mechanical response of polycarbonate nanocomposites to high velocity impact
}

PLEASE CITE THE PUBLISHED VERSION

http://dx.doi.org/10.1016/j.eurpolymj.2016.10.048

\section{PUBLISHER}

(C) The Authors. Published by Elsevier

\section{VERSION}

VoR (Version of Record)

\section{PUBLISHER STATEMENT}

This work is made available according to the conditions of the Creative Commons Attribution 4.0 International (CC BY 4.0) licence. Full details of this licence are available at: http://creativecommons.org/licenses/ by/4.0/

\section{LICENCE}

CC BY-NC-ND 4.0

\section{REPOSITORY RECORD}

Al-Lafi, Waleed, Jie Jin, and Mo Song. 2016. "Mechanical Response of Polycarbonate Nanocomposites to High Velocity Impact”. figshare. https://hdl.handle.net/2134/23122. 
Macromolecular Nanotechnology

\title{
Mechanical response of polycarbonate nanocomposites to high velocity impact
}

\author{
W. Al-Lafi, J. Jin, M. Song* \\ Department of Materials, Loughborough University, Loughborough LE11 3TU, UK
}

\section{A R T I C L E I N F O}

\section{Article history:}

Received 15 August 2016

Received in revised form 18 October 2016

Accepted 27 October 2016

Available online 28 October 2016

\section{Keywords:}

Nanocomposites

Carbon nanotubes

Impact behavior

Stress/stain curves

\begin{abstract}
A B S T R A C T
In this study, the mechanical responses of polycarbonate (PC) and PC/multi-walled carbon nanotubes (MWCNTs) to dynamic loadings at low and high velocities impacts were investigated experimentally using an instrumented falling weight impact tester (IFWIT) and a split Hopkinson pressure bar (SHPB), respectively. The results from the IFWIT tests revealed that impact strength, impact failure energy and fracture toughness were dramatically enhanced by the incorporation of a very small amount of the MWCNTs into the PC matrix. The maximum load and the impact failure energy increased by $\sim 320 \%$ and $\sim 350 \%$, respectively, when only $1 \mathrm{wt} \%$ MWCNTs was incorporated. The results from the SHPB tests demonstrate that all the materials showed strain-rate sensitivity. The MWCNTs nanocomposites exhibited higher yield stress and energy absorption characteristics compared to the PC matrix material. However, the enhancement by MWCNTs was very limited for the PC containing higher percentage of the filler at higher strain rates. This could be resulted by a thermal-softening effect. In addition, the density of the pure PC and PC/MWCNTs nanocomposite specimens before or after SHPB testing was examined to gain insight into the microstructure changes. The results show that the density decreased significantly after the SPBH tests. With increasing strain rate the density decrease in PC nanocomposite is faster than that in the pure PC. It is believed that more cracks formed in the PC nanocomposite during the SHPB tests, which could result in high energy dissipation.
\end{abstract}

(c) 2016 The Authors. Published by Elsevier Ltd. This is an open access article under the CC BY license (http://creativecommons.org/licenses/by/4.0/).

\section{Introduction}

As terrorist attacks have increased around the globe in recent years, the issue of combat survivability has become a primary concern for the public and governments [1-5]. Personal and vehicle protection from blast and ballistic impacts are more important to reduce life threatening situations to our soldiers, police force, and as well aid workers and other civilian personnel working in hostile areas. To meet the high performance requirements the protective materials must withstand many different threats, whilst maintaining performance integrity under harsh conditions. The design of personal protection body armour and vehicles must achieve a balance between needs of high protection and light weight. Once soldiers are deployed from their protected vehicles, they require lightweight body protection that allows them to operate freely at high or low temperatures and altitudes whilst carrying a full battle load. These considerations have led to an increase in interest

\footnotetext{
* Corresponding author.

E-mail address: m.song@lboro.ac.uk (M. Song).
} 
and activity levels in the homeland security, defence, and aerospace industries in the development of protection materials for applications of body armour and armed vehicles $[3,4,6]$.

Over the last few decades, due to its unique property combination of high mechanical strength, outstanding impact resistance, good chemical resistance and excellent transparency, polycarbonate (PC) has been widely used as a shield or antiballistic material in areas of military, sports and personal protection [7-10]. Blast and ballistic impacts tend to have dynamic loads that overwhelm the static load resistance of a material. Hence, the development of high performance PC-based materials at high strain rate impact is significantly important to protection against bullets, fragments, improvised weapons and other projectiles.

In recent years, the development of nano-reinforced composites materials has garnered great interest in the material science community. These materials, a synthesis of a base matrix polymer and particle, where at least one aspect of the particle is in the nanometre-scale, have been shown to improve a wide range of physical and engineering properties, e.g. stiffness, impact resistance, fracture toughness and the ability to absorb energy, of the matrix material [2,10-12]. These enhanced properties are mostly attributable to the nanoparticles' high surface area-volume ratio. At the nanoscale, there is distinct size dependence of the material properties as there is increase in interfacial area, and consequent high reactivity and interactivity. Owing to the energy absorption and dissipation nature of such nanocomposites, they have potential applications where high impact resistance is paramount. The applications of these types of materials can be found in many, widely diverse areas of engineering. However, specific examples occur more frequently in the fields of structural, military or sport engineering where resistance to high strain rate deformation is a key requirement. When a material deforms rapidly, such as in a high speed collision or impact, the mechanical response of that material can be noticeably different to the response observed by more traditional testing techniques. The impact response is strongly dependent on the temperature sensitivity, strain hardening and strain rate sensitivity of a material [13-20]. However, to date there is relatively little published work on the high strain rate deformation of polymeric material compared to metallic materials, and there are even fewer papers reporting the study of the mechanical properties of these types of nanocomposite materials at high impact strain rates. With the future application of such types of nanocomposite materials in high strain rate environments in mind, high performance PC based nanocomposites were fabricated and the impact responses of these materials under dynamic loadings at low and high velocity impacts were characterised and are discussed here.

\section{Experimental}

\subsection{Materials}

Polycarbonates (PC) with medium molecular weight polycarbonate (MFI $=21.6 \mathrm{~g} / 10 \mathrm{~min}$ ) was received from SABIC Innovative Plastics. Chemically modified multi-walled carbon nanotubes (MWCNTs) with 3-5\% OH attached on the side wall were obtained from Chengdu Institute of Organic Chemistry, Chinese Academy of Science. Average diameter of the MWCNTs is about $20 \mathrm{~nm}$, the length about $30-50 \mu \mathrm{m}$. Na ${ }^{+}$montmorillonite clay was obtained from Southern Clay Products, USA.

\subsection{Sample preparation}

PC and MWCNT or clay at different mass ratios was pre-mixed based on the method suggested in a patent [21]. Then the $\mathrm{PC} / \mathrm{MWCNT}$ or PC/clay mixtures were blended in an intermeshing counter rotating twin screw extruder. Prior to extrusion, the mixtures were dehumidified in a vacuum oven at $80^{\circ} \mathrm{C}$ for a period of $6 \mathrm{~h}$. The process was carried out at a screw speed of $100 \mathrm{rpm}$ and a temperature difference of $250,260,270$ and $280^{\circ} \mathrm{C}$ between feed zones to die zone. For preparation of impact test specimen compression moulding was applied at temperature of $280^{\circ} \mathrm{C}$ and a pressure of 20 tons. Sample size is $10 \mathrm{~cm} \times 10 \mathrm{~cm} \times 1 \mathrm{~mm}$ for the Instrumented Falling Weight Impact Test.

\subsection{Characterization}

Scanning electron microscopy (SEM) images were taken on a field emission gun SEM (FEGSEM) LEO 1530VP instrument to observe the fracture cross-sectional morphology of PC nanocomposites. Glass transition temperature of the materials was measured by using a TA instrument DSC 2920 differential calorimetry (DSC). Heating rate was $10^{\circ} \mathrm{C} / \mathrm{min}$. Impact resistance tests were performed using the Rosand Instrumented Falling Weight Impact Tester (IFWIT). ASTM D5420 standard test method was followed to assess the impact behavior of the PC and its nanocomposites. A standard dropping mass of $10 \mathrm{~kg}$ was employed on the entire specimen from a drop height of $0.5 \mathrm{~m}$ at a speed of $3.12 \mathrm{~m} / \mathrm{s}$. five specimens for each sample were tested. The impact behavior of the PC and its nanocomposites under loading at high strain rates of $3100 \mathrm{~s}^{-1}$, $3400 \mathrm{~s}^{-1}, 3800 \mathrm{~s}^{-1}$ and $4000 \mathrm{~s}^{-1}$ was examined using the SHPB at room temperature in the Department of Physics at Loughborough University. The details of the SHPB used in this research can be found in Ref. [5]. All specimens were lubricated on both surfaces by layer of petroleum jelly. Five specimens for each were tested and the tabulated values are the average of these results. Density was measured by using a calibrated density gradient column (Davenport, UK). Davenport two column density measuring instrument is ideal for high accuracy determination of the density of solid polymers (ASTM D 1505-68, 
ISO 1183 and BS 2782 Part 6: Method 620D). Accuracy of readings is to $0.0001 \mathrm{~g} / \mathrm{mL}$ with density column ranges within $0.05 \mathrm{~g} / \mathrm{mL}$. Back lighting of column aids float and sample visibility.

\section{Results and discussion}

Fig. 1 shows SEM images of the fracture surfaces of the pure PC and its composites with 0.5 and 1.0 wt\% MWCNTs. It can be clearly seen that the nanotubes were very dispersed and embedded into the PC matrix at nanoscale level.

The glass transition temperature, $T_{g}$, of the PC and its MWCNTs nanocomposites were measured by means of DSC, and the results are shown in Fig. 2. PC shows a glass transition temperature $\left(T_{\mathrm{g}}\right)$ at about $149{ }^{\circ} \mathrm{C}$ and the addition of nanofiller resulted in a slight decrease of $T_{\mathrm{g}}$. for the nanocomposite systems. This phenomenon is due to the fact that the addition of nanoparticles might create more free volume in the composites, resulting in a slight decrease in $T_{g}$.

Fig. 3 relates to the performance of the PC and its MWCNTs nanocomposites under test using an instrumented falling weight impact tester (IFWIT), where the characterization involves drawing up a history of the damage kinetics of the specimens from initiation to complete failure. As expected, the semi-crack fracture behavior was observed for the PC and its MWCNTs nanocomposites. It can be clearly seen that incorporation of MWCNTs has significant effects on the impact performance of the pure PC. The maximum load, deflection to maximum load and area of the force-deflection curve were greatly increased with increasing filler content.
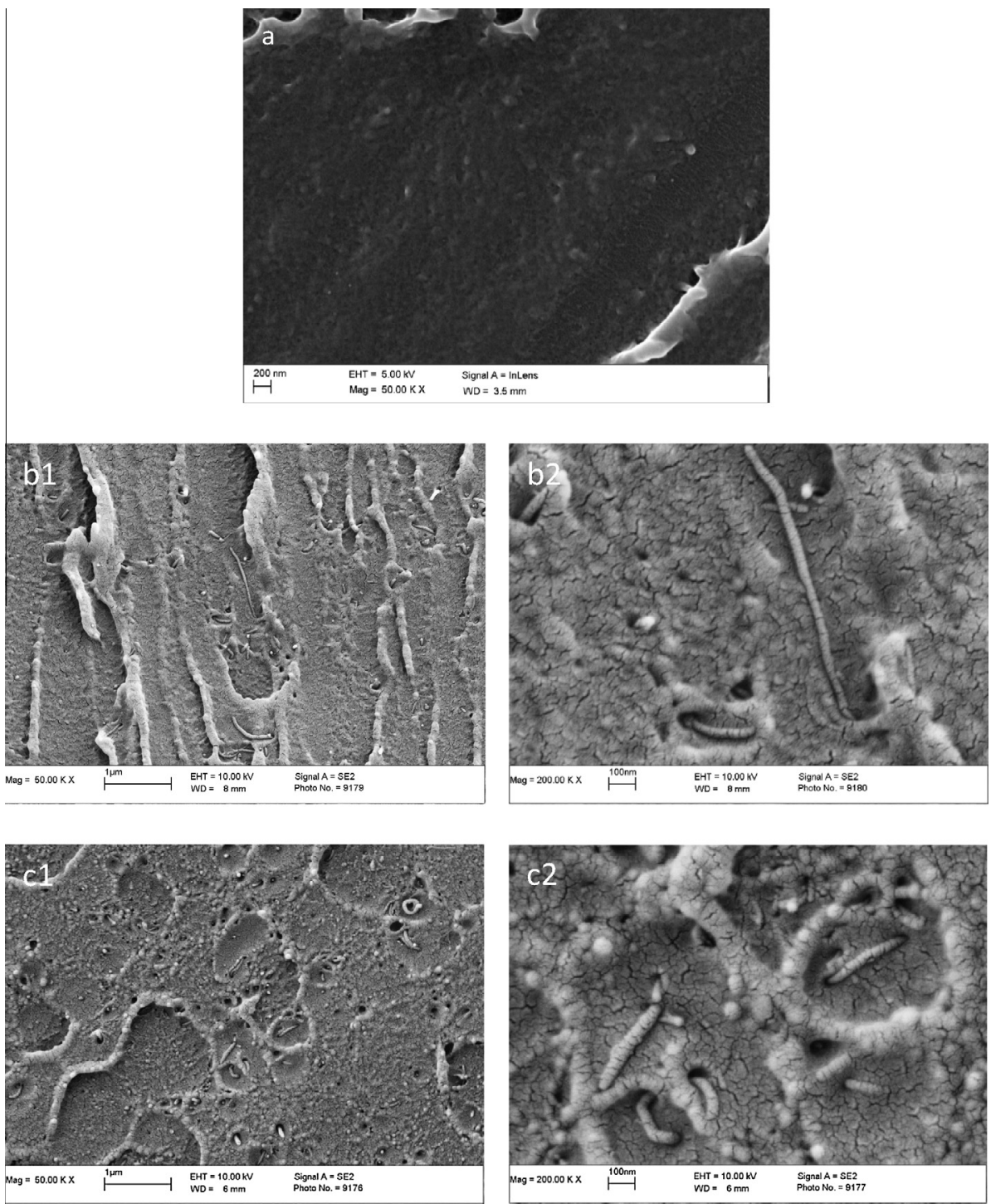

Fig. 1. SEM photomicrograph at low or highest magnification (a) PC; (b1 and b2) 0.5 wt\% MWCNTs; and (c1 and c2) 1.0 wt\% MWCNTs. 


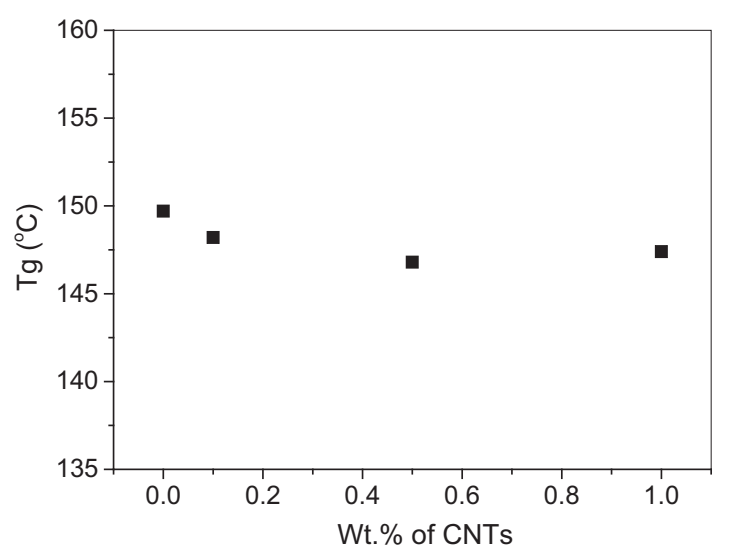

Fig. 2. Effect of MWCNT on the glass transition temperature.

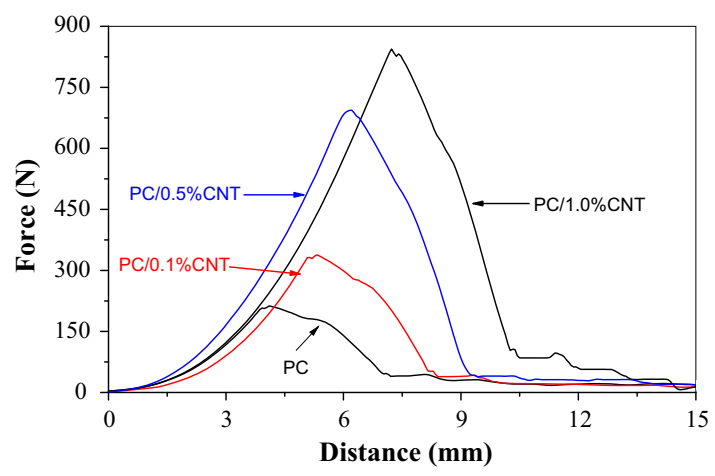

Fig. 3. Force-deflection curves of PC and PC/MWCNTs nanocomposites.

The value of the maximum load for the pure PC is about 209 N. Incorporation of MWCNTs causes a significant increase of $\sim 320 \%$ ( $884 \mathrm{~N}$ ) at $1 \mathrm{wt} \%$ MWCNTs loading. This indicates that the PC nanocomposites are able to sustain much higher external force before being broken, and the behavior contributes to greater deflection. The increased filler content leads to higher impact force due to the particle interface react and form a tortuous fracture path [22]. The gradual decrease in load after maximum load could be associated with localized cracking, leading to gradual failure.

The peak point on the maximum load curve corresponds to the radial fracture damage point. This point marks the onset of failure in the material as this initiation of damage induces a decrease in material stiffness, resulting in a drop in the load time profile. The drop in load marks the boundary line between two distinct phases, i.e. fracture initiation and fracture propagation. This implies that a higher force is needed to initiate a crack in the PC/MWCNT nanocomposite.

For a semi-fracture system the total absorbed energy can be divided into two parts. The first is required for crack initiation, the elastically stored energy in the composite plate, which is released after maximum deflection by rebounding of the sample. The second is, the energy absorbed in the material available for crack propagation that consequently controls the extent of damage and residual strength. The amounts of total energy absorbed by falling weight impact, as measured by integration of the area underneath the force-deflection curves from Fig. 3, are summarized in Table 1. As expected, the PC nanocomposite exhibited a greater amount of energy absorption than the pure PC. Quantifiably, the nanocomposite with $1 \mathrm{wt} \%$ MWCNTs loading exhibited the largest amount of energy absorption, giving an improvement, than that of the pure PC. This improvement in impact failure energy is also an evidence of increase in energy dissipation capability of PC upon the addition of the MWCNTs. As a rule of thumb, the greater the energy dissipation capability of a system, the tougher it is! Also of note, with additional MWCNTs, the energies of initiation and the energy of propagation were also increased. In order to compare the reinforcement between two parts of the energies, the percentage of initiation energy for each sample was analyzed as shown in Fig. 4. As seen, the most part of the absorbed energy was consumed within the crack-initiation stage, whereas the crack propagation contributed a small proportion of energy consumption when the sample contained higher loading of MWCNTs. During impact the nanoparticles serve as stress concentrators in the matrix to build up a stress field around themselves. Because of the weak adhesion between the particles and the polymer matrix, debonding at the particle-matrix interface took place, leading to the release of the strain constraints at the crack tip and consequent massive plastic deformation, which consumed a large amount of energy [23]. 
Table 1

Initiation energy, propagation energy and the total energy of PC/CNTs nanocomposites.

\begin{tabular}{llll}
\hline Sample & Initiation energy $\left(10^{5} \mathrm{~J} / \mathrm{m}^{3}\right)$ & Propagation energy $\left(10^{5} \mathrm{~J} / \mathrm{m}^{3}\right)$ & Total energy $\left(10^{5} \mathrm{~J} / \mathrm{m}^{3}\right)$ \\
\hline PC & 2.53 & 4.22 & 6.75 \\
PC/0.1MWCNT & 4.57 & 6.11 & 10.65 \\
PC/0.5MWCNT & 11.87 & 10.69 & 22.56 \\
PC/1MWCNT & 15.38 & 14.87 & 30.26 \\
\hline
\end{tabular}

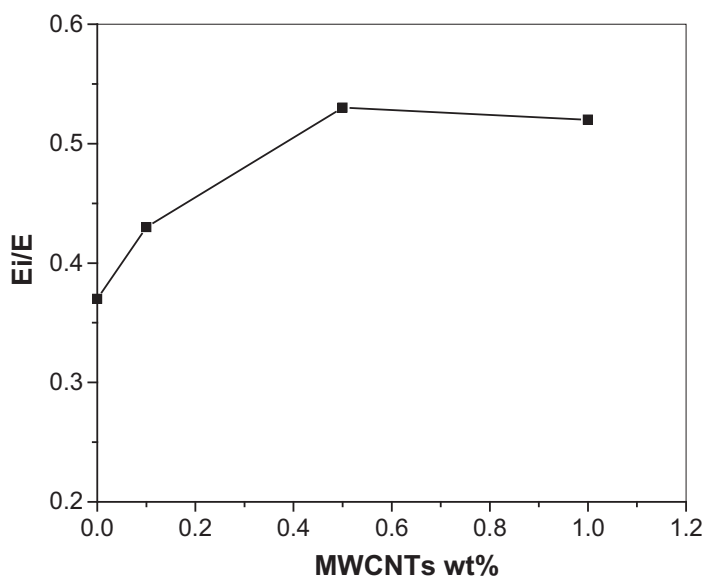

Fig. 4. Percentage of initiation energy against weight percentage of MWCNTs.
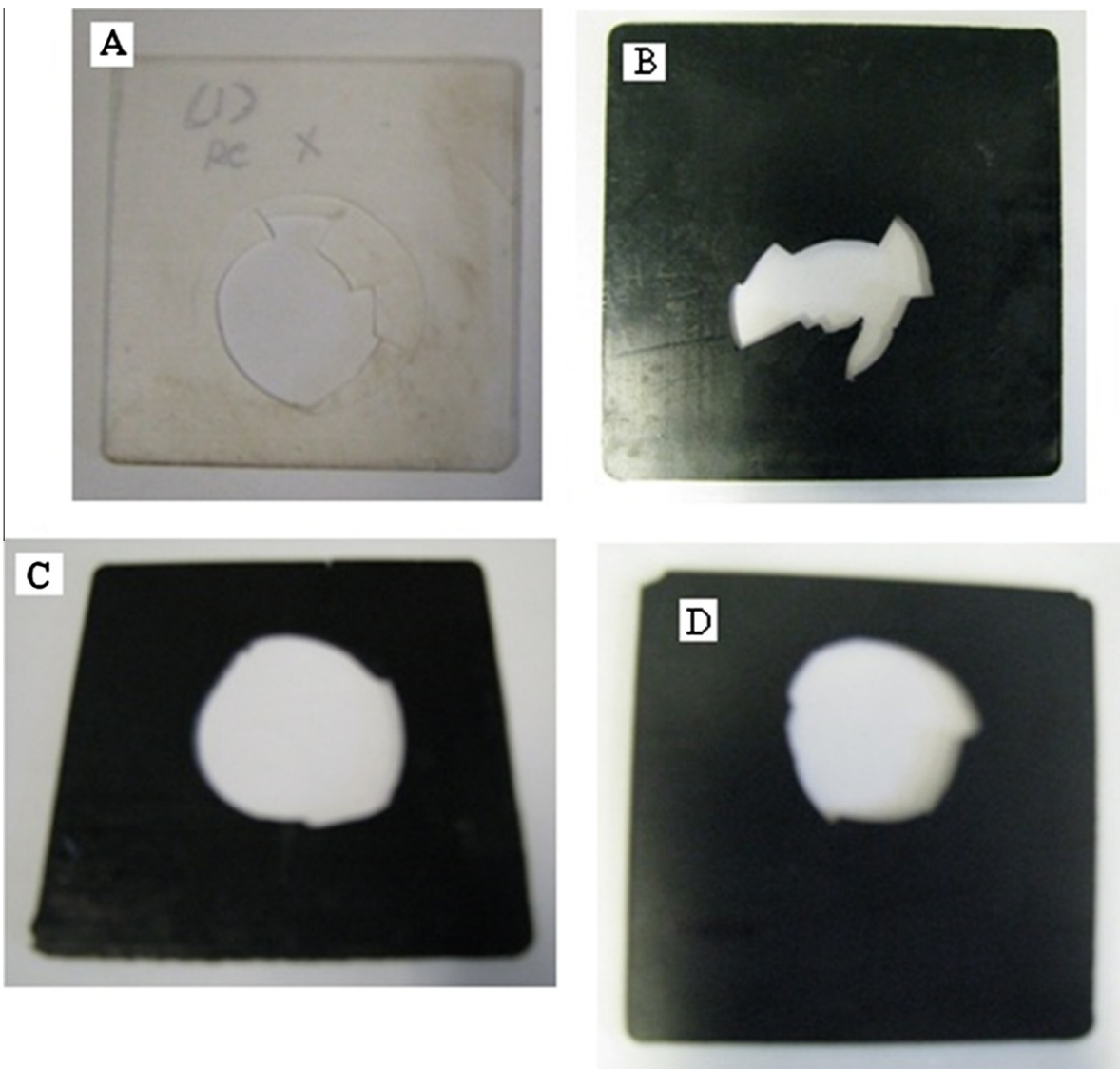

Fig. 5. Representative digital images for the PC and nanocomposites after the impact tested: (A) Pure PC; (B) 0.1 wt\% MWCNTs; (C) 0.5 wt\% MWCNTs; (D) $1 \mathrm{wt} \%$ MWCNTs (sample size $10 \mathrm{~cm} \times 10 \mathrm{~cm}$ ). 
Fig. 5 shows representative digital images for the tested specimens of the pure PC and its nanocomposites. The patterns of damage in the entire configuration were presented. For the pure PC, the crack path was erratic and brittle fracture. The sample containing $0.1 \mathrm{wt} \%$ MWCNTs shows the similar model as in the pure PC. However, the samples containing 0.5 or $1.0 \mathrm{wt} \%$ MWCNTs exhibited plastic deformed yielding zone in the area where the falling weight striker hit, though the samples are fully penetrated. This again demonstrates visible evidence for dramatic improvement in the toughness of the PC. Dispersion of nanoparticles in a polymer matrix is essential for reinforcing impact performance of the material. When large aggregates are present the voids that are created by debonding are not stable and grow to a size where crack initiation occurs. The creation of stable free volume at the particle size level could lead to high energy adsorption by shear yielding and consequently high impact resistance [24]. The SEM images as shown in Fig. 1 revealed that uniform dispersion and distribution of MWCNTs in nanoscale was achieved in the PC matrix. It could be one reason for the reinforcement of impact properties of the PC.

The PC and its nanocomposites were examined by means of an 'in-house' four-bar split Hopkinson Pressure Bar (SHPB) system for high strain rate performance. Fig. 6 shows the stress-strain response curves for the PC and its MWCNTs nanocomposites at strain rates of about $3100 \mathrm{~s}^{-1}, 3400 \mathrm{~s}^{-1}, 3800 \mathrm{~s}^{-1}$ and $4000 \mathrm{~s}^{-1}$, respectively. It was seen that the stress-strain behavior for all materials including the pure PC exhibited an initial near-linear behavior where they yielded, followed by a transitional non-linear response where strain hardening takes place prior to a strain softening behavior. Addition of the nanofiller into the PC matrix resulted in significant changes in the flow and yield stress and the area under the curves for the resulting nanocomposites. These materials were also highly strain-rate-dependent.

At high strain rates, the impact behavior of polymeric materials is very complex due to their temperature sensitivity, strain hardening and strain rate sensitivity [25]. It is believed that the impact resistance of the material at the initial stage before yield point is critical for their actual applications such as crashworthiness of automobiles and armor development. In the following paragraphs the yield stress and energy absorption from the begging to the yield point are discussed. The yield stress of all the materials shown in Fig. 7 depends on the applied strain rates. With increasing strain rate, the yield stress increased. Introduction of a very small amount of nanofiller material into the PC matrix resulted in a significant improvement in yield stress. In particularly, the nanocomposite with $1 \mathrm{wt} \%$ MWCNTs exhibited higher yield stress, giving an increase of $\sim 25 \%$ at $3100 \mathrm{~s}^{-1}$ strain rate. However, it was noted that the nano-reinforcement effect became weaker with increasing strain rate, especially for the PC containing higher MWCNTs contents. The yield stress for 1.0 wt\% nanocomposite material was increased only by $\sim 13 \%$ at the highest strain rate of $4000 \mathrm{~s}^{-1}$. Fig. 8 shows in terms of energy absorption for each material from beginning to the yield point. It can be seen that all nanocomposite materials exhibited a great amount of energy
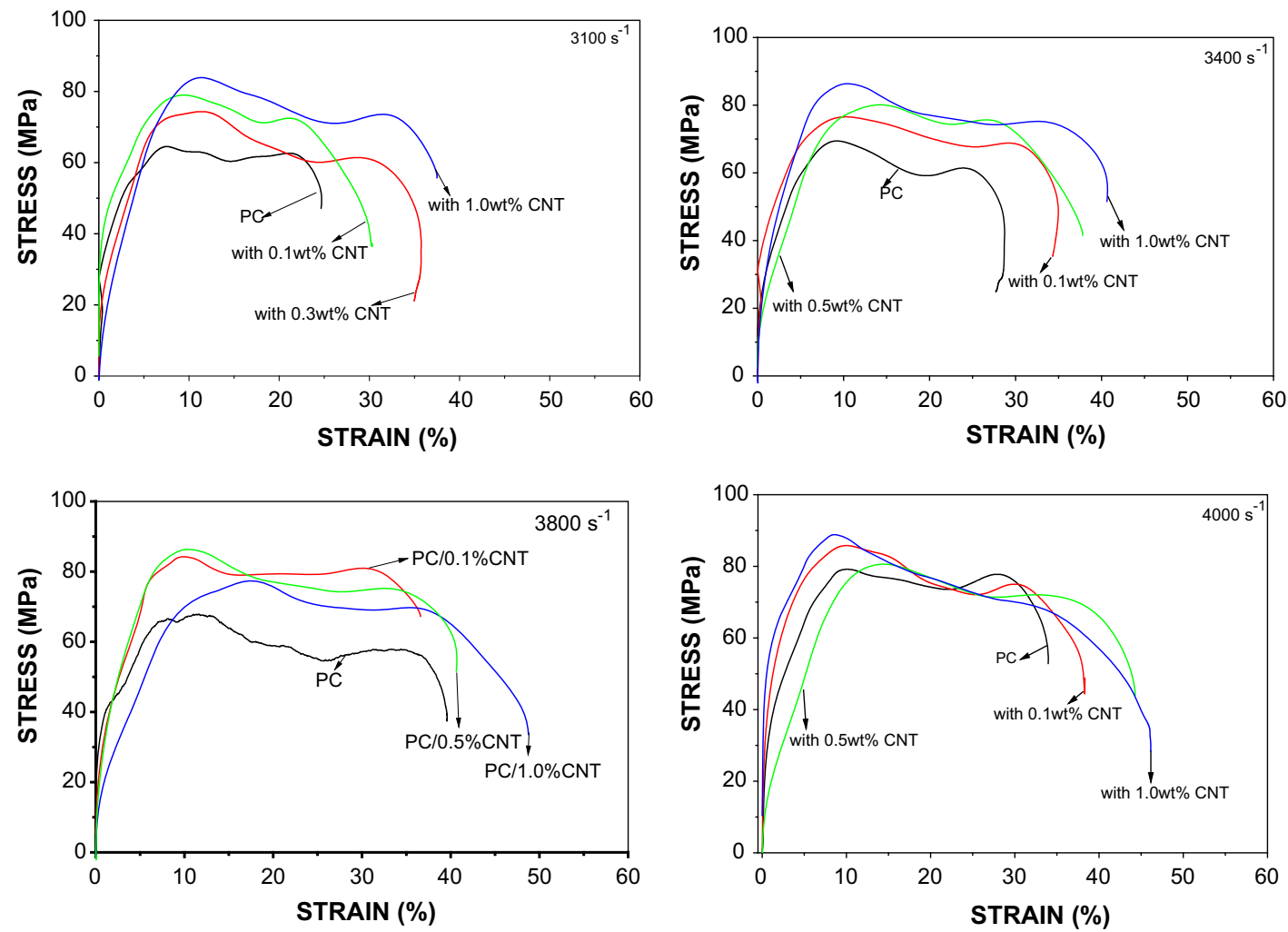

Fig. 6. Stress-strain curves for PC and its MWCNTs nanocomposites at different strain rates. 

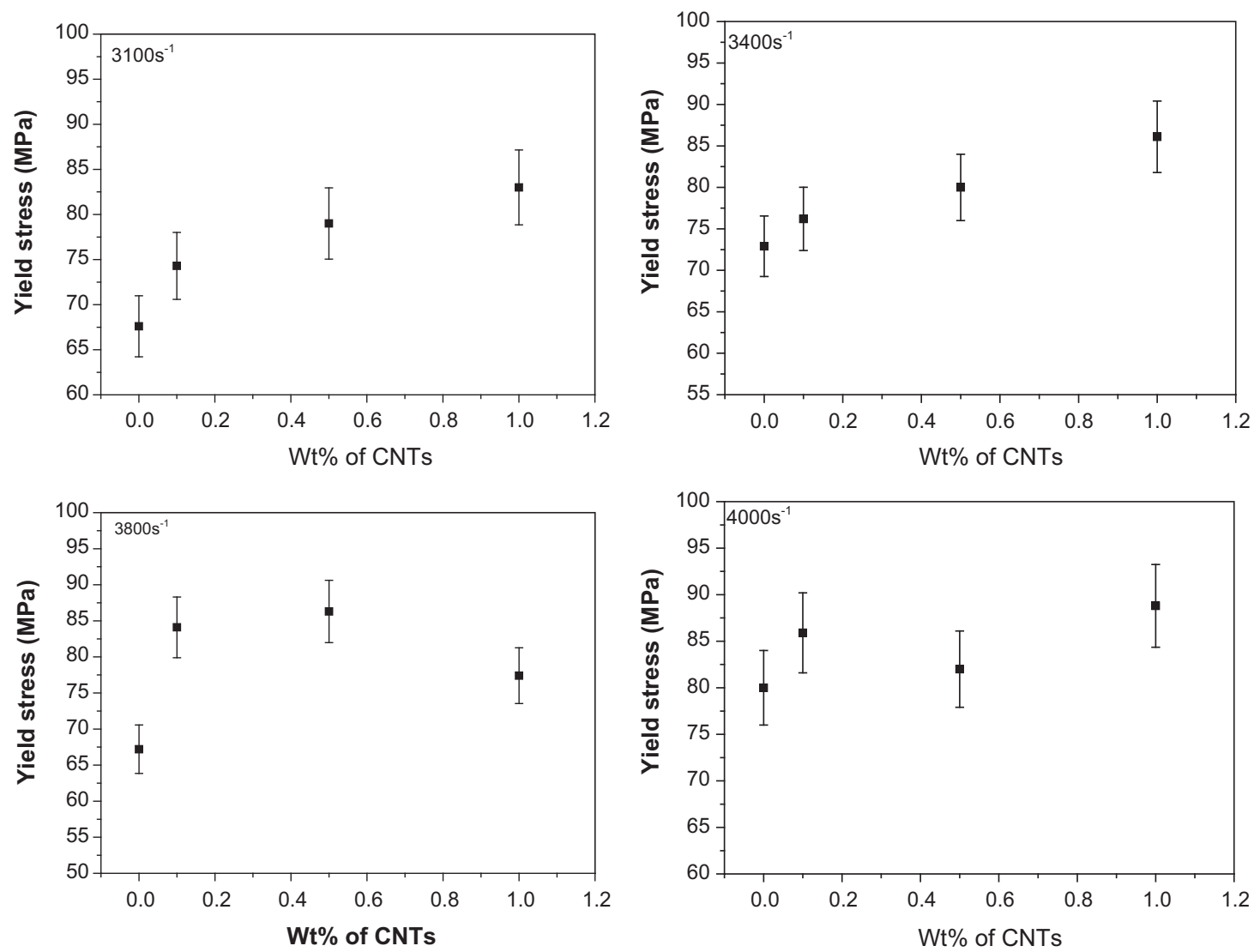

Fig. 7. Effect of MWCNTs on yield stress of PC/MWCNT nanocomposites at different strain rates.

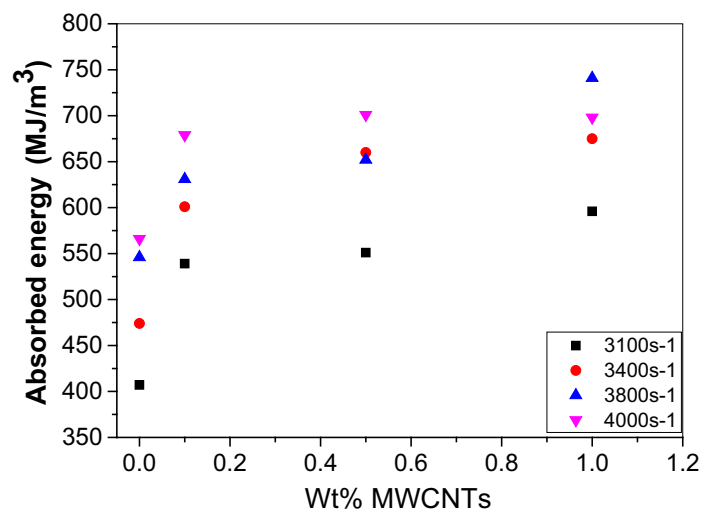

Fig. 8. Effect of MWCNTs on absorbed energy of PC/MWCNT nanocomposites at different strain rates (from beginning to yield point).

absorption than that of the pure PC. For example, for 1 wt\% MWCNT nanocomposite the energy absorption increased by $\sim 15 \%$ at $3100 \mathrm{~s}^{-1}$ strain rate. Again, when the strain rate was increased from $3800 \mathrm{~s}^{-1}$ to $4000 \mathrm{~s}^{-1}, 1 \mathrm{wt} \%$ MWCNTs nanocomposite did not show an obvious increment of the energy absorption. In order to understand this phenomenon, a comparison study for PC/clay nanocomposites was done at the same high strain rates. Fig. 9 shows energy absorption for PC/clay nanocomposites at different strain rates. The energy absorption characteristic is similar in PC/MWCNT system. With increasing the strain rate or clay content the absorbed energy increased. However, the nano-reinforcement effect was also achieved even though for the PC containing higher percentage of $2 \mathrm{wt} \%$ clay at highest strain rate.

For most polymeric materials it is common to find that high temperature levels can be rapidly induced when the material is being deformed at a higher strain rate, where the test is performed quickly [26]. Heat will be generated by converting the 


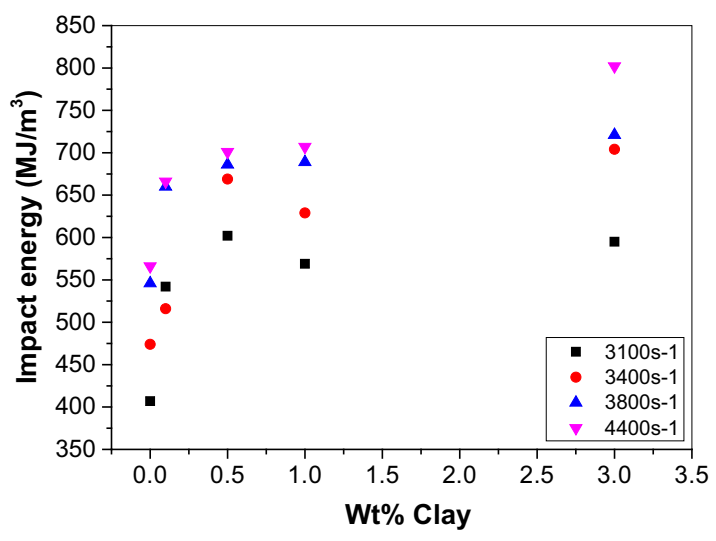

Fig. 9. Effect of Clay on absorbed energy of PC/Clay nanocomposites at different strain rates (from beginning to yield point).

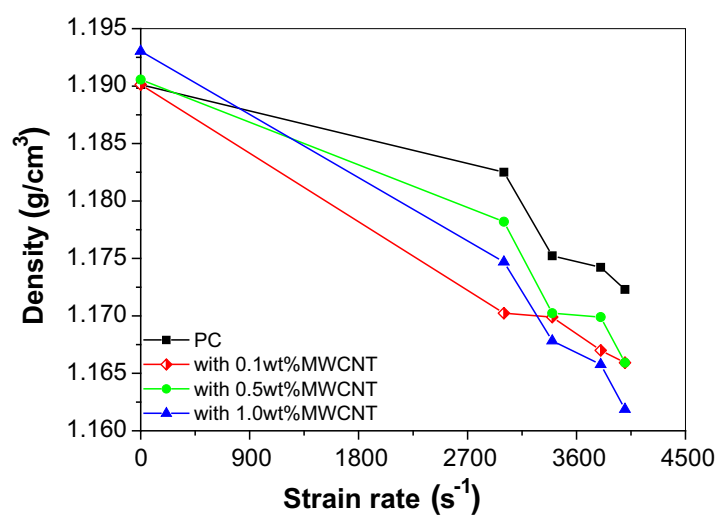

Fig. 10. Density of $P C$ and $P C / M W C N T s$ nanocomposites with strain rates.

plastic energy through irreversible thermodynamic processes. This leads to thermal softening and degradation of their mechanical properties [27]. It can be assumed that for a polymer nanocomposite material being at a high strain rate impact, the present nanofiller material, which has a higher thermal conductivity, could result a rapid, significant increase in the local temperature in the interfaces, especially for higher filler loadings. High heat generation in the interfaces could lead the material softening as the interfacial bonds weaken. Comparing to the clay nanofiller, the thermal conductivity of MWCNTs is much higher. This could be the reason for some influences in nano-reinforcement effect for the PC/MWCNTs system at higher strain rate as discussed above. It is clear that the thermal-softening effect could result in a reduction of the nanoreinforcement effect. According to the above discussion, for the development of high performance nanocomposite materials to be applied in situations where there is a high resistance to loading at high strain rates, such as impact or blast deformation, it would be better to use such reinforcement nanofillers with lower thermal conductivity.

After the SHPB tests, the microstructure of samples could be changed due to applied high speed impact. However, it is difficult to clearly observe the damaged specimens using SEM because of the limitation for preparing SEM specimens. In order to gain insight into the changes of microstructure in the PC and its nanocomposites, the density of the specimens before or after the SHPB tests was measured and the results are shown in Fig. 10. The results indicated that after the SHPB tests, the density of the pure PC and its nanocomposites decreased and the density drop with increasing strain rate in the nanocomposites was faster than that in the pure PC. This illustrates that more cracks formed in the PC nanocomposites during the SHPB tests. The decrease in density with increasing strain rate could result in the formation of a large amount of cracks during the SHPB tests. The more cracks form, the more energy dissipates. This could be the reason why the increase in impact energy with increasing strain rate in PC/MWCNT nanocomposite is greater than in the PC.

\section{Conclusions}

PC and its MWCNTs nanocomposites with $0.1,0.5$ and $1 \mathrm{wt} \%$ content were assessed for their impact resistance behavior under dynamic loadings. The results from the IFIM tests indicate that MWCNTs were significantly effective in improving the impact resistance of the PC at very low filler loadings. In particular, the maximum load and the impact failure energy were 
dramatically increased by $\sim 320 \%$ and $\sim 350 \%$, respectively, when only 1 wt\% MWCNTs was incorporated. The performance of the PC and its nanocomposite at high strain rates of $3100 \mathrm{~s}^{-1}, 3400 \mathrm{~s}^{-1}, 3800 \mathrm{~s}^{-1}$ and $4000 \mathrm{~s}^{-1}$ examined by the SHPB showed that all the materials exhibited appreciable strain-rate sensitivity and the incorporation of MWCNTs lead to increase in yield stress and impact energy absorption. For $1 \mathrm{wt} \%$ MWCNT nanocomposite, the yield stress and impact energy increased greatly by $\sim 25 \%$ and $\sim 15 \%$, respectively, at the high strain rate of $3100 \mathrm{~s}^{-1}$ as compared to the PC matrix. This improvement was understood by studying the changes in the densities of the materials before and after the SHPB tests. The decreased density illustrates that more cracks were formed in the PC nanocomposite during the SHPB tests, which could result in high energy dissipation. However, the nano-reinforcement effect at higher strain rate can have significant influences by involving the thermal-softening effect, especially for the PC nanocomposite containing higher MWCNT content. According to the comparison study, it would be better to use low thermal conductive reinforcement nanofiller for the fabrication of polymer nanocomposite materials for use in situations involving impact loadings such as crashworthiness of automobiles and armor development.

\section{Acknowledgement}

We thank EPSRC (UK) for providing funding (EP/G042756) for this work.

\section{References}

[1] P.C. Branco, H. Schubert, Defense Industries: Science and Technology Related to Security: Impact of Conventional Munitions on Environment and Population, Kluwer, Dordrecht, 2004. <http://www.springerlink.com/content/h8217505w677n656>.

[2] X. Sha, Effects of Sonication on the Kinetics and Mechanical Properties of Vinyl Ester Nanocomposites. PhD's thesis, Pittsburg State University, 2008.

[3] C.C. Ibeh, M. Bubacz, ASM AEROMAT, 2008.

[4] N. Zhou, A. Beyle, C.C. Ibeh, Adv. Mater. Res. 47 (50) (2008) 1133-1136.

[5] A.J. Prudom, Performance of multi-component polymers at high strain rates. PhD's Thesis Loughborough University, UK, 2012.

[6] D.G. LeGrand, Mechanical properties of polycarbonates, in: D.G. LeGrand, J.T. Bendler (Eds.), Handbook of Polycarbonate Science and Technology, Marcel Dekker, Inc., New York, 2000, p. 107.

[7] H.T. Pham, C.L. Weckle, J.M. Ceraso, Adv. Mater. 12 (2000) 1881-1885.

[8] S. Balakrishnan, N.R. Neelakantan, S.N. Jaisankar, J. Appl. Polym. Sci. 74 (1999) 2102-2110.

[9] D.R. Paul, L.M. Robeson, Polymer 49 (2008) 3187-3352.

[10] R.R. Maharsia, H.D. Jerro, Mater. Sci. Eng., A 45 (2007) 416-422.

[11] J. Jin, L. Chen, M. Song, J. Nanosci. Nanotechnol. 9 (2009) 6453-6459.

[12] J.A. Roetling, Polymer 6 (1965) 311-317.

[13] J.A. Roetling, Polymer 6 (1965) 615-619.

[14] C. Bauwens-Crowet, J.C. Bauwens, G. Homès, J. Polym. Sci., Part B: Polym. Phys. 7 (1969) $735-742$.

[15] J.C. Bauwens, C. Bauwens-Crowet, G. Homès, J. Polym. Sci., Part B: Polym. Phys. 7 (1969) 1745-1754.

[16] C. Bauwens-Crowet, J.C. Bauwens, G. Homès, J. Mater. Sci. 7 (1972) 176183.

[17] M.F. Omar, H.M. Akil, Z.A. Ahmad, Mater. Sci. Eng. 528 (2011) 1567-1576.

[18] X. Li, Y. Yan, L. Guo, C. Xu, Polym. Test. 52 (2016) 254-264.

[19] Y.G. Miao, Y.L. Li, H.Y. Liu, Q. Deng, L. Shen, et al, Int. J. Mech. Sci. 108 (109) (2016) 188-196.

[20] K.H. Safari, J. Zamani, R.M. Guedes, F.J. Ferreira, Mech. Time-Depend. Mater. 20 (2016) 45-64.

[21] M. Song, D. Cai, J. Jin. US 13/257589, 2010.

[22] J.C. Lin, L.C. Chang, H.M. Nien, H.L. Ho, Compos. Struct. 74 (2006) 30-36

[23] W.C.J. Zuiderduin, C. Westzaan, J. Huetink, R.J. Gaymans, Polymer 44 (2002) 261-275.

[24] A.M. Riley, C.D. Paynter, P.M. Mcgenity, J.M. Adams, Plast. Rub. Proc. Appl. 14 (1990) 85-93.

[25] L.C.S. Nunes, F.W.R. Dias, H.S. Costa, D. Mattos, Polym. Test. 30 (2011) 70791-70796.

[26] C.M. Roland 79 (2006) 429-459.

[27] I.A. Ashcroft, C.V. Gorwade, A.S. Alghamdi, V.V. Silberschmidt, M. Song, Key Eng. Mater. 557 (2014) $493-496$. 